\title{
MOLECULAR CHARACTERIZATION OF B-AGARASE PRODUCED BY SPHINGOMONAS PAUCIMOBILIS, A MARINE BACTERIUM
}

Arunmozhi Bharathi Achudhan, V. Mahalakshmi*

Address (es):

Research Scholar, Department of Microbiology, Madras Christian College, East Tambaram, Chennai-59, Tamilnadu.

*Corresponding author: mahalakshmi@mcc.edu.in

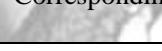

https://doi.org/10.36547/be.159

\section{ABSTRACT}

Agarases are enzymes that catalyze the hydrolysis of agar. The present study was carried out to isolate the agar degrading microorganisms from marine source. The characterization of agar degrading organism was done by VITEK 2.0 automated instrument, which confirmed the sample as Spinghomonas paucimobilis by a set of 64 biochemical tests. Production of agarase, an extracellular enzyme was done in mineral salt broth with agar and the enzyme was purified by ammonium sulphate precipitation and dialysis. The molecular weight of the enzyme was determined by SDS-PAGE method. Fourier transform infrared spectroscopy analysis was done to authenticate the degree of degradation of agar. The presence of agarase gene was targeted using the required primers and amplified by Polymerase chain reaction. Also the study addresses the problem of solid waste generation of agar waste by any microbiological laboratories and industries.

Keywords: Agarase, Agar degradation, Marine bacteria

\section{INTRODUCTION}

Agar is a polysaccharide and it is obtained from some species of algae belonging to the phylum Rhodophytes. Red algae's cell wall is the major component of agar and has been used in a variety of medical laboratories and industrial applications, mainly for its jellifying properties. Agar is made up of agarose and small molecules called Agaropectin (Xiao Ting Fu and Sang Moo Kim 2010). Agar has been used as an ingredient in desserts throughout Asia, and also as a solid substrate to contain culture media for microbiological work. Agar can be used as a laxative, an appetite suppressant, a vegetarian substitute for gelatin, a thickener for soups, in fruit preserves, ice cream, and other desserts, as a clarifying agent in brewing, and for sizing paper and fabrics (Edward Balfour,1987).

Some microorganisms produce an enzyme called agarase, which can hydrolyze and metabolise agar as a carbon source and energy source and these are called as agarolytic microorganisms. According to their cleavage pattern they are classified into three types $\alpha$-agarase, $\beta$-agarase and $\beta$-porphyranase. Although all the agarases are involved in complete hydrolysis of agar, most of the discoveries reveal that $\beta$-agarase has higher efficiency ( Won-Jae Chi et al., 2012) Agarase enzymes have many applications like agar hydrolysis for production of oligosaccharides for essential physiological and biological activities that are helpful for human health and therefore they are used in food industry, cosmetics and medical fields (Linda J. Ross, 1970)

There have been numerous reports on agarase from isolates belonging to genera of the domain Bacteria, including Acinetobacter, Agarivorans, Alteromonas, Bacillus, Cytophaga, Microbulbifer, Pseudoalteromonas, Pseudomonas, Salegentibacter, Thalassomonas, Vibrio, Zobellia, etc., (Hu $\mathbf{Z}$ et al.,2009) many of which are of marine origin. The present study aimed at isolating agar degrading bacteria from marine source, since agarase enzyme is produced in conditions of high salinity. Discarding agar medium is usually done in all medical laboratories and industries which eventually results in clogging of drainage systems and gives problem to society. Thus the solid generation in all life science laboratories and industries can be reduced by these agarolytic microorganisms. The study aimed at the isolation of agar degrading bacteria from marine source and the biochemical characterization of the isolate followed by enzyme assay for the agarase enzyme produced and FTIR to authenticate agar degradation. Molecular characterization of agarase gene by PCR amplification was also attempted.

\section{MATERIALS AND METHOD}

Agar degrading bacteria were found mostly in marine water, so water samples were collected from Besant nagar beach and Mahaballipuram beach, Culture media, VITEK 2.0 instrument, Buffers, Dialysis bag, SDS-PAGE apparatus and gel, Master mix and Thermocycler.

\section{Isolation of organisms}

Isolation of bacteria from marine water samples was carried out by standard serial dilution agar plating method on a selective, Zobell marine agar medium since it has high amount of salts that mimics the sea water. Spread plate method was carried out to get isolated colonies and the inoculated plates were incubated at $37{ }^{\circ} \mathrm{C}$ for $48 \mathrm{hrs}$.

\section{Screening of microorganisms}

The isolated colonies were inoculated into three different $10 \mathrm{ml}$ agar tubes and incubated. The best degrading organism was selected based on their degradation effect.

\section{Characterization of agar degrading bacterial isolate}

Identifying the genus and species name of the selected organism was done by VITEK 2 automated instrument.

The VITEK 2 system is really fast and gives accurate microbial identification with antibiotic susceptibility testing. The microbial identification system includes an expanded identification database that gives rapid results. The VITEK 2 system platform provides greater automation while increasing safety and eliminating repetitive manual operations. The rapid response time means results can be provided more quickly than with manual microbial identification techniques (https://www.biomerieux-usa.com/vitek-2).

\section{Enzyme assay}

For Enzyme production the screened culture was inoculated in mineral salt broth with small amount of agar as carbon source and incubated for 10 days at $37{ }^{\circ} \mathrm{C}$ (Lakshmikanth M et al.,2006).

\section{Extraction and partial purification of agarolytic enzymes}

Following incubation $1 \mathrm{ml}$ of culture was taken in a eppendorf tube and $1 \mathrm{ml}$ of Phosphate buffer solution (pH 7.4) and $2 \mathrm{ml}$ of $36 \%$ of Na2SO4 were added. The mixture was mixed and stirred gently for 30 minutes at room temperature followed by centrifugation at $5000 \mathrm{rpm}$ for 10 minutes and the supernatent was discarded. The precipitate was washed twice with $18 \% \mathrm{Na} 2 \mathrm{SO} 4$, centrifuged and again the supernatent was discarded. Now the precipitate was dissolved in $0.8 \mathrm{ml}$ of PBS, equal quantity of $24 \% \mathrm{Na} 2 \mathrm{SO} 4$ solution was added and centrifuged at $5000 \mathrm{rpm}$ for 10 minutes. Finally, the precipitate was washed with $12 \% \mathrm{Na} 2 \mathrm{SO} 4$ and redissolved in $1 \mathrm{ml}$ of PBS. The content was transferred to dialysis bag and dialysed extensively at $4^{\circ} \mathrm{C}$ against PBS (Hiroshi Maeda et al., 2005) and the protein concentration was determined by SDS - PAGE method.

\section{Electrophoresis of enzymes}

Sodium dodecyl sulfate-polyacrylamide gel electrophoresis (SDS-PAGE) was performed to identify the partially purified enzyme. The separating gel $(15 \%)$ was prepared and poured into the glass plate set up and allowed for polymerization. This was followed by adding stacking gel before the comb was placed. The sample was mixed with gel loading dye and kept in water bath for 5 minutes at $100^{\circ} \mathrm{C}$. This sample was loaded on to the gel and electrophoresed at 
100 volts. After electrophoresis, the gel was stained and kept for 12 hours and then de-stained (Sambrook J et al., 1989).

\section{Spectroscopic study}

The FTIR instrument sends infrared radiation of about 10,000 to $100 \mathrm{~cm}^{-1}$ through a sample, with some radiation absorbed and some passed through. The absorbed radiation is converted into rotational and/or vibrational energy by the sample molecules.

The resulting signal at the detector presents as a spectrum, typically from 4000 $\mathrm{cm}^{-1}$ to $400 \mathrm{~cm}^{-1}$, representing a molecular fingerprint of the sample. Each molecule or chemical structure will produce a unique spectral fingerprint, making FTIR analysis a great tool for chemical identification (Griffiths, P.R and de Haseth, J.A.,2007).

FTIR (Fourier-transform infrared spectroscopy) analysis was done to authenticate the degree of degradation of agar. For FTIR study, films were made from partially degraded agar media (FIGURE 1). Both positive and control films were made and the samples were given to IIT Madras, Guindy campus, Chennai (outsourcing) to run the FTIR test.

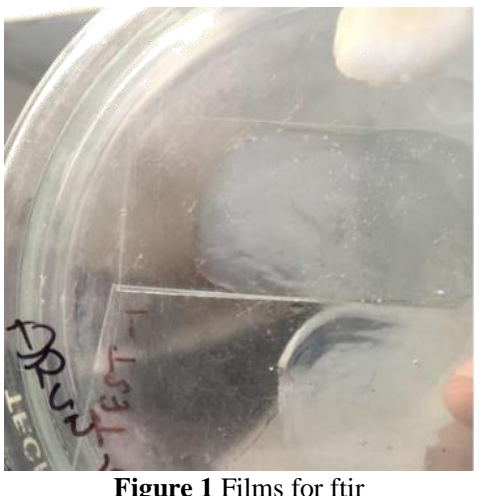

Targetting the agarase gene

The polymerase chain reaction is an enzyme catalyzed biochemical reaction in which small amount of the specific DNA sequences are amplified into large amounts of linear double stranded DNA (Mullis, 1990). PCR is used to amplify the DNA sequence in between two known sequences. For targeting the agarase gene, the specific primers (forward and reverse primers) complementary to the known sequences were added along with the master mix. (GeNoRime, Lexus Scientific, Chennai) to the DNA and the mixture was placed in a thermocycler heated at $94^{\circ} \mathrm{C}$ for denaturation of the DNA. The mixture was then allowed to cool enabling the primers to anneal to the complementary sequences. A heat stable DNA polymerase was used to make the copies of the DNA from the original DNA sequence. Thirty cycles of the DNA amplification was performed.

Two primers annealing at the 5 ' and 3 ' end of the DNA were:

Forward Primer - 5'-GGATCCATGAAAACCACTCAGGGCG -3'

Reverse primer - 5'-CAAGCTTTTAATTACTTAGCACGAACTTATCC -3'

\section{Setting up the pcr reaction}

A fresh master mix which contained 10X Taq buffer, $10 \mathrm{mM}$ dNTPs, $25 \mathrm{mM}$ of $\mathrm{MgCl} 2,1 \mathrm{U}$ of Taq DNA polymerase, $1.5 \mu 1$ of forward primer, $1.5 \mu 1$ of Reverse primer, $100 \mathrm{ng}$ of Genomic DNA was prepared and the final volume was made to $20 \mu \mathrm{l}$ using PCR grade molecular water. After addition of all the components the PCR tube was gently spun down in micro centrifuge briefly and was placed in the thermocycler. The thermocycler was programmed as follows.

Program 1 - one cycle - Initial denaturation

$$
\text { 1. } 95^{\circ} \mathrm{C} \text { for } 2 \text { minutes. }
$$

Program 2 - 30 cycles - Amplification

$$
\begin{aligned}
& \text { 1. Denaturation }-95^{\circ} \mathrm{C} \text { for } 30 \text { seconds } \\
& \text { 2. } \quad \text { Annealing }-56^{\circ} \mathrm{C} \text { for } 30 \text { seconds } \\
& \text { 3. } \quad \text { Extension }-72^{\circ} \mathrm{C} \text { for } 30 \text { seconds }
\end{aligned}
$$

Program 3 - one cycle - Final extension

1. $72^{\circ} \mathrm{C}$ for 5 minutes, then hold at $4^{\circ} \mathrm{C}$.

The programmed temperatures of the PCR reaction was represented in the diagram as shown below,

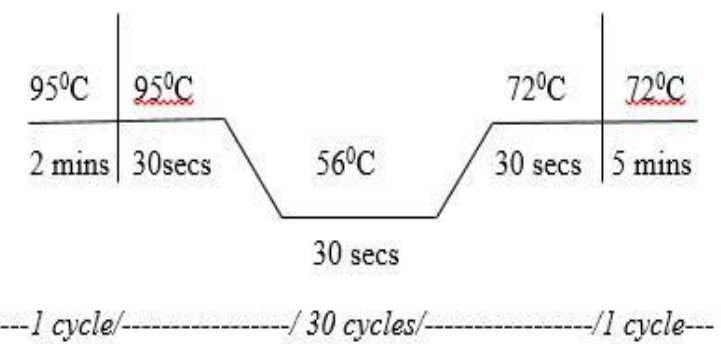

The amplified DNA was subjected to agarose gel electrophoresis along with the marker DNA (DNA Ladder) and based on the size of the amplified (DNA) fragment, it was confirmed that the specific agarase gene was amplified.

\section{RESULTS AND DISCUSSION}

\section{Isolation and screening of agar degrading bacteria}

Following 48 hours of incubation three types of colonies were isolated on Zobell agar medium and these colonies were further inoculated into three different $10 \mathrm{ml}$ agar tubes for degradation test.

\section{Degradation test}

The tubes were observed for degradation on a daily basis. The degradation started on the second day and liquefied agar was observed on the $10^{\text {th }}$ day (figure $2 \mathrm{a}$, figure $2 b$, figure $2 c)$.

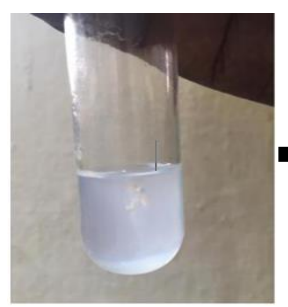

Figure 2a - 2 ${ }^{\text {nd }}$ day

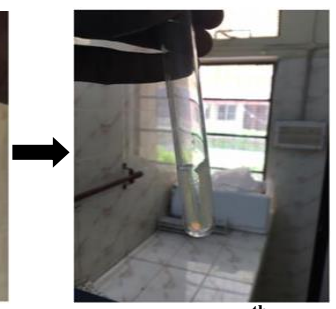

Figure $2 \mathrm{~b}-\mathbf{5}^{\text {th }}$ day

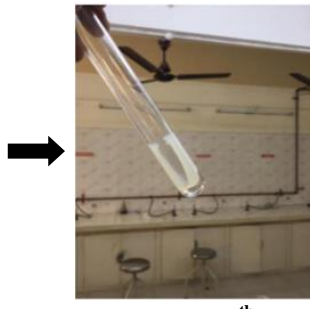

Figure $2 \mathrm{c}-10^{\text {th }}$ day
The efficient agar degrading culture was selected and sub cultured for further studies.

\section{Characterization of agar degrading organism}

The organism was identified as Sphingomonas paucimobilis by VITEK 2.0 automated instrument.

In previous study the agar degrading organisms isolated were found to be Vibro sp JT0107, Cytophaga sp , Agarivorans albus, Zobellia galactanivorans, Vibrio sp.PO-303. These organisms also were found to produce $\beta$-agarase, whereas the organism Thalassomonas $s p$. producing $\alpha$-agarase was reported by Xiao Ting Fu and Sang Moo Kim in the year 2010. In the present study, three different organisms were isolated and based on the degradation efficiency, one organism 
was selected for further studies. The organism was identification by VITEK 2.0 automated instrument as Spingomonas paucimobilis and the class of agarase produced was known to be of $\beta$ agarase category.

\section{Enzyme assay}

After de-staining of polyacrylamide gel, the band of agarase enzyme was recorded under UV transilluminator (figure 3).

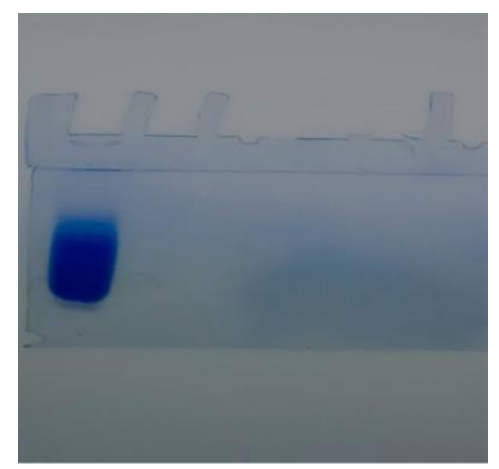

Figure 3 Band on poly acrylamide gel electrophoresis

Previous studies had revealed that the agar degrading organisms were isolated from the plant roots, the organism being Asticcacaulis sp.SA7, which produced extracellular $\alpha$ - agarase enzyme (Akifumi Hosoda \& Masao Sakai (2006)). In this study the marine water sample was used due to the high condition of salinity. Microorganisms produced $\beta$ - agarase in an environmental condition of high salinity. The result very much correlated with the studies of Wandong Fu et al., (2008), which stated about the purification and characterization of agarases from a marine bacterium Vibrio Sp. F-6. Marine bacterium Vibrio Sp. F-6, utilizing agarose as a carbon source to produce agarases, was isolated from seawater samples taken from Qingdao, China. Two agarases (AG-a and AG-b) were purified to a homogeneity from the cultural supernatant of Vibrio sp. F-6 through ammonium sulfate precipitation, Q-Sepharose FF chromatography, and Sephacryl S-100 gel filtration. Molecular weights of agarases were estimated to be $54.0 \mathrm{kDa}$ (AG-a) and $34.5 \mathrm{kDa}$ (AG-b) by sodium dodecyl sulfatepolyacrylamide gel electrophoresis (SDS-PAGE). Thus in the current study, enzyme assay was done to confirm the presence of the extracellular agarase enzyme after partial purification by ammonium sulphate precipitation and dialysis followed by SDS-PAGE method and the molecular weight was found to be $34.5 \mathrm{kda}$ thus proving the production of $\beta$-agarase by the isolate.

\section{Fourier transform infrared spectroscopy}

The spectral values of the test sample were compared with the control. The deviation of the spectral values from $500 \mathrm{~cm}^{-1}$ to $1700 \mathrm{~cm}^{-1}$ in the test sample indicated agar degradation (figure 4).

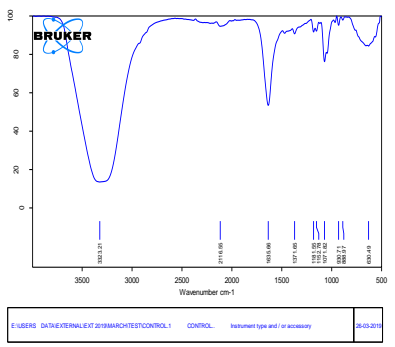

Control sample

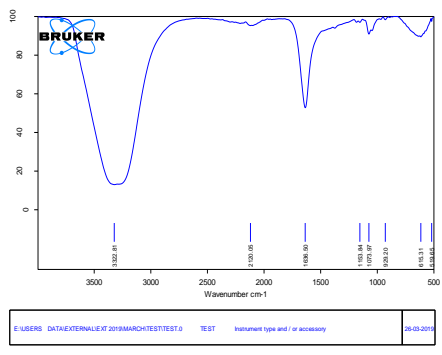

Test sample
Figure 4 FTIR of control vs test

Fourier transform infrared spectroscopy analysis was done to authenticate the degree of degradation of agar by forming thin film and the shift in spectral values was compared with normal agar film.

\section{Targeting the agarase gene}

The agarase gene was amplified following polymerase chain reaction (figure 5).

\section{Amplified product}

Extraction of the genomic DNA of the microbial culture was done using direct extraction technique and the quality and intactness of the extracted DNA was examined by running on $1 \%$ agarose gel. The agarase gene was targeted and amplified via polymerase chain and the band of the amplified product was obtained again by agarose gel electrophoresis.

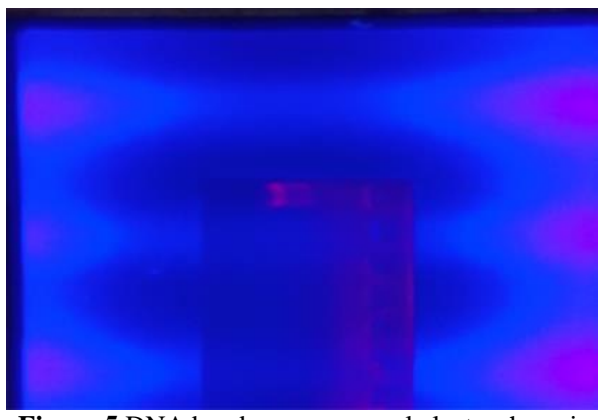

Figure 5 DNA band on agarose gel electrophoresis

\section{CONCLUSION}

Thus this study is significant in addressing the disposal of agar wastes by Microbiological laboratories and industries and also emphasise the need to design a new solidifying agent in culture media to isolate the marine microorganisms capable of degrading agar. The study aims at safeguarding the Environment, since the solid generation in all life science laboratories and industries can be reduced and the hence clogging of the drainage systems can be avoided.

Author agreement statement: We the undersigned declare that the manuscript is original, has not been published before and is not currently being considered for publication elsewhere.

We confirm that the manuscript has been read and approved by all named authors and that there are no other persons who satisfied the criteria for authorship but are not listed. We further confirm that the order of authors listed in the manuscript has been approved by all of us.

We understand that the Corresponding Author is the sole contact for the Editorial process. She is responsible for communicating with the other authors about progress, submission of revisions and final approval of proofs.

Funding source: The authors declare that no fund was received from any funding agency for this research work.

Conflict of interest: The authors declare that there is no conflict of interest.

\section{REFERENCES}

Akifumi Hosoda \& Masao Sakai (2006). Isolation of

Asticcacaulis sp. SA7, a Novel Agar-Degrading Alphaproteobacterium. Bioscience, $\begin{array}{lll}\text { Biotechnology, and } & \text { Biochemistry,70:3.722- }\end{array}$ 725.https://doi.org/10.1271/bbb.70.722

Edward Balfour. Cyclopaedia of India and of eastern and southern Asia, commercial, industrial and scientific: products of the mineral, vegetable and animal kingdoms, useful arts and manufactures. Food and Agriculture Organization, United Nations. 1987. McHugh DJ. https://archive.org/details/cyclopdiaindiaa00unkngoog/page/n11/mode/2up Griffiths, P.R and de Haseth, J.A.: Fourier Transform InfraredSpectrometry, 2nd Edn, $\quad$ Wiley, 2007. https://onlinelibrary.wiley.com/doi/pdf/10.1002/9780470106310.fmatter Hu Z, Lin BK, Xu Y, Zhong M, Liu GM (2009) Production and purification of agarase from a marine agarolytic bacterium Agarivorans sp. HZ105. J Appl Microbiol 106:181-190. https://doi.org/10.1111/j.1365-2672.2008.03990.x 
Hiroshi Maeda, Youhei Yamagata, Keietsu Abe, Fumihiko Hasegawa, Masayuki Machida, Ryoji Ishioka, Katsuya Gomi \& Tasuku Nakajima (2005). Purification and characterization of a biodegradable plastic-degrading enzyme from Aspergillus oryzae. Applied Microbiology and Biotechnology volume 67, pages778-788.https://doi.org/10.1007/s00253-004-1853-6

Linda J. Ross. The Enzymic hydrolysis of Neoagarotetraose, a thesis submitted to the Facu1ty of Graduate Studies and Research in partial fulfillment of the requirements for the degree of Masters of Science Department of Microbiology and Immunology McGi11 University Montreal June, 1970. http://www.iosrjournals.org/iosr-jpbs/papers/Vol13-issue3/Version-

3/A1303030107.pdf

Lakshmikanth M, Manohar S, Souche Y, Lalitha J. Extracellular $\beta$-agarase LSL1 producing neoagarobiose from a newly isolated agar-liquefying soil bacterium, Acinetobacter sp., AG LSL-1.World J Microbiol Biotechnol. 2006; 22:10871094.https://doi.org/10.1007/s11274-006-9147-z

Sambrook J, Fritschi EF and Maniatis T (1989) Molecular clon-ing: a laboratory manual, Cold Spring Harbor Laboratory Press, New York. https://www.cshlpress.com/pdf/sample/2013/MC4/MC4FM.pdf

VITEK $^{\circledR}$ 2: Healthcare. https://www.biomerieux-usa.com/vitek-2

Won-Jae Chi and Yong-Keun Chang and Soon-Kwang Hong. Agar degradation by microorganisms and agar degrading enzymes. Appl Microbiol Biotechnol (2012) 94:917-930.https://doi.org/10.1007/s00253-012-4023-2

Wandong Fu., Baoqin Han., Delin Duan (2008). Purification and characterization of agarases from a marine bacterium Vibrio Sp. F-6. Journal of Industrial Microbiology and Biotechnology 35(8):915-22.https://doi.org/10.1007/s10295008-0365-2

Xiao Ting Fu and Sang Moo Kim (2010). Agarase review of major sources, categories, purification method, enzyme characteristics and applications. Marine drugs 2010, 8, 200-218.https://doi.org/10.3390/md8010200 